\title{
Effect of Renin-Angiotensin System Blockage in Patients with Acute Respiratory Distress Syndrome: A Retrospective Case Control Study
}

\author{
Joohae Kim', Sun Mi Choi ${ }^{2}$, Jinwoo Lee ${ }^{2}$, Young Sik Park ${ }^{2}$, Chang Hoon Lee ${ }^{2}$, Jae-Joon Yim², Chul-Gyu Yoo ${ }^{2}$, \\ Young Whan Kim², Sung Koo Han ${ }^{2}$, and Sang-Min Lee ${ }^{2}$ \\ ${ }^{1}$ Center for Lung Cancer, Research Institute and Hospital, National Cancer Center, Goyang; ${ }^{2}$ Seoul National University Hospital and Department of Internal Medicine, Seoul National \\ University College of Medicine, Seoul, Korea
}

Background: Acute respiratory distress syndrome (ARDS) remains a life-threatening disease. Many patients with ARDS do not recover fully, and progress to terminal lung fibrosis. Angiotensin-converting enzyme (ACE) inhibitor is known to modulate the neurohormonal system to reduce inflammation and to prevent tissue fibrosis. However, the role of ACE inhibitor in the lungs is not well understood. We therefore conducted this study to elucidate the effect of renin-angiotensin system (RAS) blockage on the prognosis of patients with ARDS.

Methods: We analyzed medical records of patients who were admitted to the medical intensive care unit (ICU) at a tertiary care hospital from January 2005 to December 2010. ARDS was determined using the Berlin definition. The primary outcome was the mortality rate of ICU. Survival analysis was performed after adjustment using propensity score matching.

Results: A total of 182 patients were included in the study. Thirty-seven patients (20.3\%) took ACE inhibitor or angiotensin receptor blocker (ARB) during ICU admission, and 145 (79.7\%) did not; both groups showed similar severity scores. In the ICU, mortality was $45.9 \%$ in the RAS inhibitor group and $58.6 \%$ in the non-RAS inhibitor group $(P=0.166)$. The RAS inhibitor group required a longer duration of mechanical ventilation ( 29.5 vs. $19.5, P=0.013$ ) and longer ICU stay ( 32.1 vs. 20.2 days, $P<0.001)$. In survival analysis, the RAS inhibitor group showed better survival rates than the non-RAS group $(P<0.001)$.

Conclusions: ACE inhibitor or ARB may have beneficial effect on ARDS patients.

Key Words: acute respiratory distress syndrome; angiotensin-converting enzyme inhibitors; angiotensin receptor antagonists; mortality; renin-angiotensin system.

\section{Introduction}

Acute respiratory distress syndrome (ARDS) is a refractory hypoxemic respiratory failure with bilateral lung infiltrates, in the absence of left atrial hypertension or evidence of volume overload [1,2].

The ARDS is associated with high mortality rates, which vary widely from $30 \%$ to $70 \%$ in several reports $[3,4]$. Although the annual ARDS mortality rates have shown improvement in several studies [5,6], ARDS remains a life-threatening disease with high mortality.

\footnotetext{
Received on December 3, 2016 Revised on May 15, 2017 Accepted on May 15, 2017

Correspondence to: Sang-Min Lee, Seoul National University Hospital and Department of Internal Medicine, Seoul National University College of Medicine, 101 Daehak-ro, Jongno-gu, Seoul 03080, Korea

Tel: +82-2-2072-0833, Fax: +82-2-762-9662, E-mail: sangmin2@snu.ac.kr

*No potential conflict of interest relevant to this article was reported.
}

(cc) This is an Open Access article distributed under the terms of the Creative Commons Attribution Non-Commercial License (http:/creativecommons.org/ licenses/by-nc/4.0/) which permits unrestricted non-commercial use, distribution, and reproduction in any medium, provided the original work is properly cited. Copyright (c) 2017 The Korean Society of Critical Care Medicine 
One of major pathophysiologic mechanisms in the early phase of ARDS is known to be endothelial injury and alveolar epithelial damage from proinflammatory cascade [7], leading to the process of proliferation and fibrosis [8]. Inflammatory biomarkers such as tumor necrosis factoralpha, interleukin 6, platelet activating factor are known to involve in ARDS pathogenesis [9-11]. In the advanced stage, activated alveolar fibrocytes, fibroblasts and myofibroblasts may drive fibroproliferation, although the process remains unclear [12]. These inflammatory cytokines and increased pulmonary fibrosis predict unfavorable outcome and higher mortality $[13,14]$. Therefore, the anti-inflammatory therapy or prevention of pulmonary fibrosis in ARDS could be targets of therapy to improve survival.

Angiotensin II exerts proinflammatory responses through activating nuclear factor- $\kappa \mathrm{B}$ in monocytes [15]. The renin-angiotensin system (RAS) inhibitors, such as angiotensin-converting enzyme (ACE) inhibitor or angiotensin receptor blocker (ARB) reduces nuclear factor- $\kappa \mathrm{B}$ activation and lipopolysaccharide induced lung neutrophil recruitment [15-17]. Rats with acute lung injury showed lower lung injury score or alveolar collagen deposit when treated with captopril and they suggested inhibition of ACE could offer protective effects on acute lung injury [18-21]. The mechanism is supposed that captopril attenuates lung fibrosis by abrogating apoptosis in lung epithelial cells.

ACE inhibitor is also well known to have a protective effect against fibrosis and remodeling, notably in the liver, kidneys and heart [22-24]. However, there was little evidence that ACE inhibitor played a protective role in human ARDS.

We hypothesized that ACE inhibitor could provide beneficial effects for ARDS patients by protecting them from prolonged inflammation and fibrosis. Therefore, we conducted this study to determine whether there is a difference in clinical outcomes including mortality rates in ARDS patients according to the use of ACE inhibitor or ARB.

\section{Materials and Methods}

\section{1) Patients population}

We retrospectively reviewed the medical records and radiographs of patients admitted to the medical intensive care unit (MICU) at a tertiary care hospital for mechanical ventilation support between January 2005 and December 2010. Eligibility criteria were that patients were: (1) over 20 years of age, and (2) fulfilled the Berlin definition: acute onset within 1 week of a known clinical insult or new or worsening respiratory symptoms; bilateral opacities not fully explained by effusions, lobar/lung collapse, or nodules; respiratory failure not fully explained by cardiac failure or fluid overload; arterial hypoxemia with $\mathrm{PaO}_{2} / \mathrm{FiO}_{2}$ lower than 300 (positive end-expiratory pressure [PEEP] or continuous positive airway pressure, $\geq 5 \mathrm{cmH}_{2} \mathrm{O}$ ) [25]. We excluded patients who were not intubated within 24 hours of ICU transfer or did not stay in the ICU for more than 48 hours following admission. Patients who were intubated and transferred from outside were also excluded.

\section{2) Study design and data collection}

Patients were classified into two groups according to whether or not they took ACE inhibitor/ARB after ICU admission (RAS inhibitor group and non-RAS inhibitor group, respectively). The study was approved by the institutional review board and ethics committee (No. H-1206-090-414). No consent from the participants was needed.

Demographic data (age, gender), risk factors for ARDS and etiology of ARDS were evaluated. We also calculated the $\mathrm{PaO}_{2} / \mathrm{FiO}_{2}$ ratio, Sequential Organ Failure Assessment (SOFA) score (at admission, 48 hours and 96 hours after admission) and Acute Physiology and Chronic Health Evaluation (APACHE) II score (within 24 hours after admission). Medication histories were reviewed to find the patients who took ACE inhibitor or ARB after ICU admission, and to collect data about the generic name, dose and duration of medication.

The primary outcome was ICU mortality, and second- 
Table 1. Baseline characteristics

\begin{tabular}{|c|c|c|c|c|c|c|}
\hline \multirow[b]{2}{*}{ Variable } & \multicolumn{3}{|c|}{ Unmatched cohort } & \multicolumn{3}{|c|}{ Propensity matched cohort } \\
\hline & $\begin{array}{l}\text { Non-RAS inhibitor } \\
\text { group }(n=145)\end{array}$ & $\begin{array}{l}\text { RAS inhibitor group } \\
\qquad(\mathrm{n}=37)\end{array}$ & P-value & $\begin{array}{l}\text { Non-RAS inhibitor } \\
\text { group }(\mathrm{n}=34)\end{array}$ & $\begin{array}{l}\text { RAS inhibitor group } \\
\quad(n=34)\end{array}$ & P-value \\
\hline Age (yr) & $63.3 \pm 13.7$ & $67.4 \pm 13.5$ & 0.104 & $70.1 \pm 13.7$ & $68.1 \pm 12.2$ & 0.514 \\
\hline Male sex & $106(73.1)$ & $28(75.7)$ & 0.751 & $27(79.4)$ & $25(73.5)$ & 0.567 \\
\hline \multicolumn{7}{|l|}{ Comorbidity } \\
\hline Hypertension & $34(23.5)$ & $20(54.1)$ & $<0.001$ & $14(41.2)$ & $15(44.1)$ & 0.806 \\
\hline Diabetes & $39(26.9)$ & $13(35.1)$ & 0.322 & $10(29.4)$ & $13(38.2)$ & 0.442 \\
\hline Coronary artery disease & $11(7.6)$ & $5(13.5)$ & 0.256 & $5(14.7)$ & $5(14.7)$ & 1.000 \\
\hline COPD & $9(6.2)$ & $2(5.4)$ & 0.855 & $1(2.9)$ & $2(5.9)$ & 0.555 \\
\hline Tuberculosis & $25(17.2)$ & $4(10.8)$ & 0.340 & 7 (20.6) & $4(11.8)$ & 0.323 \\
\hline Chronic liver disease & $17(11.7)$ & $2(5.4)$ & 0.262 & $1(2.9)$ & $2(5.9)$ & 0.555 \\
\hline Chronic kidney disease & $8(5.5)$ & $12(32.4)$ & $<0.001$ & $8(23.5)$ & $11(32.4)$ & 0.417 \\
\hline Cerebral vascular accident & $7(4.8)$ & $4(10.8)$ & 0.173 & $4(11.8)$ & $3(8.8)$ & 0.690 \\
\hline Malignancy & $92(63.5)$ & $12(35.3)$ & 0.003 & $10(29.4)$ & $12(35.3)$ & 0.604 \\
\hline Pulmonary & $17(18.5)$ & $3(25.0)$ & 0.590 & $3(30.0)$ & $3(25.0)$ & 0.793 \\
\hline Extrapulmonary & $75(81.5)$ & $9(75)$ & - & $7(70.0)$ & $9(75.0)$ & - \\
\hline Injury mechanism & & & 0.789 & & & 1.000 \\
\hline Direct & $127(87.6)$ & $33(89.2)$ & & 30 (88.2) & 30 (88.2) & \\
\hline Indirect & 18 (12.4) & $4(10.8)$ & & $4(11.8)$ & $4(11.8)$ & \\
\hline ARDS severity & & & 0.431 & & & 0.200 \\
\hline Mild & $7(4.8)$ & $3(8.6)$ & & 0 & $3(8.8)$ & \\
\hline Moderate & $70(47.6)$ & $13(37.1)$ & & $12(35.3)$ & $12(35.3)$ & \\
\hline Severe & $70(47.6)$ & $19(54.3)$ & & $22(64.7)$ & $22(64.7)$ & \\
\hline \multicolumn{7}{|l|}{ PF ratio } \\
\hline Initial & $112.2 \pm 45.4$ & $103.1 \pm 51.7$ & 0.297 & $93.9 \pm 33.4$ & $103.0 \pm 53.6$ & 0.407 \\
\hline $24 \mathrm{hr}$ after admission & $144.5 \pm 73.0$ & $144.9 \pm 69.9$ & 0.974 & $133.4 \pm 68.2$ & $149.2 \pm 71.1$ & 0.353 \\
\hline 72 hr after admission & $173.1 \pm 90.9$ & $187.8 \pm 113.6$ & 0.408 & $150.1 \pm 81.8$ & $193.8 \pm 116.1$ & 0.081 \\
\hline Discharge day & $141.5 \pm 114.3$ & $164.6 \pm 124.2$ & 0.282 & $132.9 \pm 113.4$ & $173.3 \pm 125.8$ & 0.168 \\
\hline APACHE II score & $31.5 \pm 6.2$ & $30.3 \pm 5.2$ & 0.316 & $29.5 \pm 6.8$ & $30.2 \pm 5.0$ & 0.612 \\
\hline \multicolumn{7}{|l|}{ SOFA score } \\
\hline Initial & $11.1 \pm 2.9$ & $10.8 \pm 2.5$ & 0.542 & $10.1 \pm 2.7$ & $10.6 \pm 2.5$ & 0.462 \\
\hline 48 hr after admission & $10.9 \pm 3.8$ & $9.5 \pm 2.5$ & 0.031 & $11.1 \pm 4.1$ & $9.4 \pm 2.3$ & 0.051 \\
\hline 96 hr after admission & $10.2 \pm 3.8$ & $9.3 \pm 2.8$ & 0.190 & $10.1 \pm 3.9$ & $9.1 \pm 2.7$ & 0.246 \\
\hline \multicolumn{7}{|l|}{ Mechanical ventilation } \\
\hline PEEP $\left(\mathrm{cmH}_{2} \mathrm{O}\right)$ & $6.9 \pm 2.6$ & $6.9 \pm 2.6$ & 0.681 & $7.6 \pm 2.9$ & $6.7 \pm 2.6$ & 0.184 \\
\hline Pressure above PEEP $\left(\mathrm{cmH}_{2} \mathrm{O}\right)$ & $18.9 \pm 4.7$ & $18.8 \pm 4.2$ & 0.845 & $18.8 \pm 4.2$ & $18.4 \pm 3.9$ & 0.639 \\
\hline $\mathrm{FiO}_{2}$ & $0.71 \pm 0.21$ & $0.71 \pm 0.19$ & 0.928 & $0.75 \pm 0.19$ & $0.71 \pm 0.20$ & 0.351 \\
\hline Tidal volume $(\mathrm{m} / \mathrm{kg})$ & $7.4 \pm 1.9$ & $7.5 \pm 1.9$ & 0.774 & $7.3 \pm 2.0$ & $7.5 \pm 1.9$ & 0.612 \\
\hline Minute volume $(L)$ & $9.8 \pm 2.9$ & $9.5 \pm 3.0$ & 0.603 & $8.8 \pm 2.8$ & $9.5 \pm 3.1$ & 0.382 \\
\hline Steroid & $89(61.4)$ & $21(56.8)$ & 0.608 & $14(41.2)$ & $19(55.9)$ & 0.225 \\
\hline CRRT & $34(23.5)$ & $7(18.9)$ & 0.556 & 7 (20.6) & $6(17.7)$ & 0.758 \\
\hline NO gas & $56(38.6)$ & $17(46.0)$ & 0.417 & $13(38.2)$ & $15(44.1)$ & 0.622 \\
\hline Inotropics & $131(90.3)$ & $29(78.4)$ & 0.046 & 30 (88.2) & $26(76.5)$ & 0.203 \\
\hline
\end{tabular}

Values are presented as mean \pm standard deviation or number (\%).

RAS: renin-angiotensin system; COPD: chronic obstructive pulmonary disease; ARDS: acute respiratory distress syndrome; PF: $\mathrm{PaO}_{2} / \mathrm{FiO}_{2} ; \mathrm{APACHE}$ : Acute Physiology and Chronic Health Evaluation; SOFA: Sequential Organ Failure Assessment; PEEP: positive end-expiratory pressure; CRRT: continuous renal replacement therapy. 
ary outcomes we measured by length of stay in ICU, ICU readmission rate, reintubation rate, radiologic improvement (decreased consolidation or infiltrates on chest radiography at ICU discharge compared to ICU admission) weaning failure rate (rate of reintubation within 48 hours after extubation) and 28- and 90-day in-hospital mortality.

\section{3) Statistical analysis}

Quantitative variables are expressed as mean \pm standard deviation, and qualitative variables are expressed as numbers and percentages. Differences between independent groups were assessed by paired t-tests for quantitative data and chi-square tests for qualitative variables. We used propensity score matching to reduce the bias caused by confounding variables. The propensity score covariates included age, gender, preexisting disease (hypertension, diabetes, coronary artery disease, chronic obstructive pulmonary disease, tuberculosis, chronic liver disease, chronic kidney disease, and malignancy) and clinical disease severity scores (SOFA score and APACHE II score). Patients with similar propensity scores in each group were matched with 1 to 1 ratio. Outcomes were compared in both unmatched and matched cohort. In the ICU and hospital, mortalities were estimated with the Kaplan-Meier analysis and log-rank test using propensity score matching analysis. All statistical analyses were performed using Stata version 13.0 (Stata Corp., College Station, TX, USA). A P-value $<0.05$ was considered to indicate a significant difference.

\section{Results}

We reviewed the records of 3,309 patients admitted to the ICU between January 2005 and December 2010. Of the 294 patients who satisfied the inclusion criteria, 112 patients were excluded, leaving 182 patients for the final analysis. After the propensity score matching, 34 patients in each group were analyzed (Figure 1).

Of the 182 patients, 134 (74\%) were male and the mean age was $64.1 \pm 13.7$ years. Thirty-seven patients received ACE inhibitor and ARB during their ICU stay. Table 1 presents the patients' demographic characteristics and history of underlying disease. History of hypertension and chronic kidney disease were significantly higher in the RAS inhibitor group. Though history of malignancy was higher in patients in the non-RAS inhibitor group, patients with lung cancer were higher in RAS inhibitor group. ( $\mathrm{P}=0.590)$ No difference in the proportion of direct lung injury was observed between the two groups.

Eighty-nine patients (48.9\%) were classified as severe ARDS according to the Berlin definition. Proportion of patients with severe ARDS was higher in the RAS inhibi-

Table 2. Cause of ICU admission

\begin{tabular}{lccc}
\hline Cause & Total $(\mathrm{n}=182)$ & Non-RAS inhibitor group $(\mathrm{n}=145)$ & RAS inhibitor group $(\mathrm{n}=37)$ \\
\hline Pulmonary & & & \\
\hline Pneumonia & $136(74.7)$ & $112(76.2)$ & $24(68.6)$ \\
\hline Hemorrhage & $10(5.5)$ & $6(4.1)$ & $4(11.4)$ \\
\hline Exacerbation of ILD & $4(2.8)$ & $3(2.0)$ & $2(5.7)$ \\
\hline Extrapulmonary & & & $1(2.9)$ \\
\hline Bacteremia & $11(6.0)$ & $10(6.8)$ & $3(8.6)$ \\
\hline Postoperative & $5(2.75)$ & $2(1.4)$ & 0 \\
\hline Transfusion related & $4(2.2)$ & $4(2.2)$ & 0 \\
\hline Drug related & $2(1.1)$ & $2(1.4)$ & 0 \\
\hline Radiation related & $1(0.6)$ & $1(0.7)$ & $1(2.9)$ \\
\hline Unknown & $8(4.4)$ & $7(4.8)$ & \\
\hline
\end{tabular}

Values are presented as number (\%)

ICU: intensive care unit; RAS: renin-angiotensin system; ILD: interstitial lung disease. 
tor group (54.3\%) than non-RAS inhibitor group (47.6\%) without statistical significance $(\mathrm{P}=0.431)$. Proportions of patients with mild ARDS were $4.8 \%$ and $8.6 \%$, those with moderate ARDS were $47.6 \%$ and $37.1 \%$ in non-RAS inhibitor group and RAS inhibitor group, respectively.

We analyzed the $\mathrm{PaO}_{2} / \mathrm{FiO}_{2}$ ratio (initial, 24 hours, 72 hours), SOFA score (initial, 48 hours, 96 hours), and APACHE II score and found no differences between the two groups.

The average PEEP levels were about $6.9 \mathrm{cmH}_{2} \mathrm{O}$ in both groups $(\mathrm{P}=0.681)$. Tidal volumes were also similar, those values were $7.4 \pm 1.9 \mathrm{ml} / \mathrm{kg}$ and $7.5 \pm 1.9 \mathrm{ml} / \mathrm{kg}$,

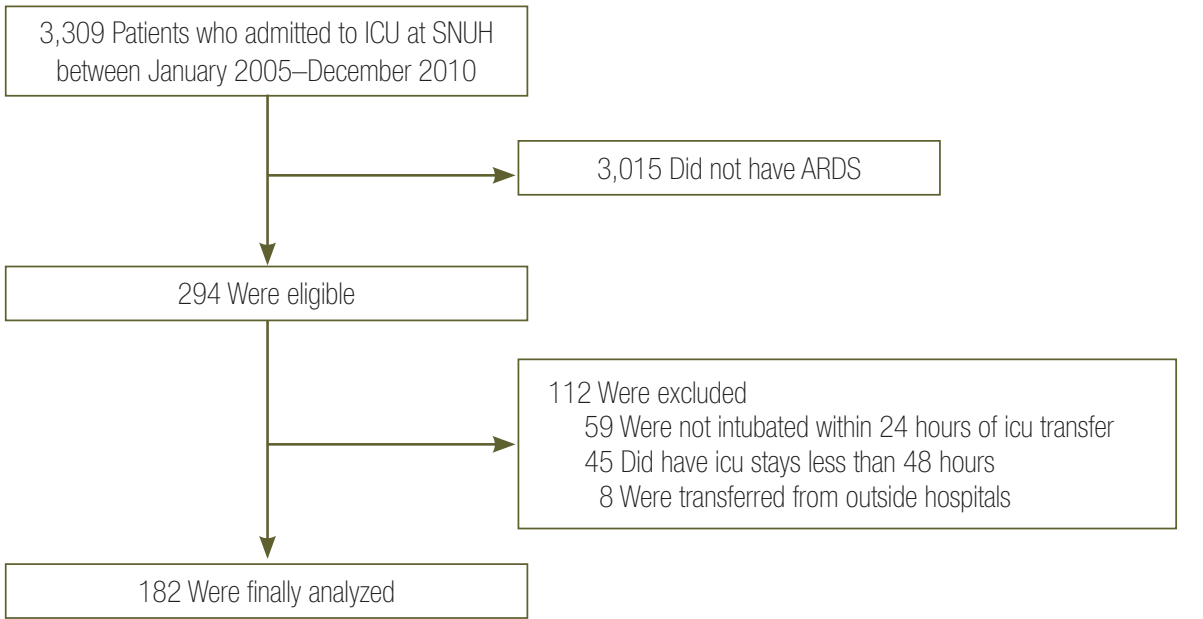

Figure 1. Enrollment and analysis of patients. ICU: intensive care unit; SNUH: Seoul National University Hospital; ARDS: acute respiratory distress syndrome.

Table 3. Primary and secondary outcomes according to study group

\begin{tabular}{|c|c|c|c|c|c|c|}
\hline \multirow[b]{2}{*}{ Variable } & \multicolumn{3}{|c|}{ Unmatched cohort } & \multicolumn{3}{|c|}{ Propensity matched cohort } \\
\hline & $\begin{array}{c}\text { Non-RAS inhibitor } \\
\text { group }(n=145)\end{array}$ & $\begin{array}{l}\text { RAS inhibitor } \\
\text { group }(n=37)\end{array}$ & P-value & $\begin{array}{c}\text { Non-RAS inhibitor } \\
\text { group }(n=34)\end{array}$ & $\begin{array}{l}\text { RAS inhibitor } \\
\text { group }(n=34)\end{array}$ & P-value \\
\hline Duration of mechanical ventilation (d) & $19.5 \pm 21.9$ & $29.5 \pm 20.8$ & 0.013 & $16.4 \pm 8.6$ & $30.2 \pm 21.5$ & $<0.001$ \\
\hline Radiologic improvement & $69(47.6)$ & $22(59.5)$ & 0.197 & $17(50.0)$ & $21(61.8)$ & 0.329 \\
\hline ICU readmission & $4(2.8)$ & $2(5.4)$ & 0.421 & $2(5.9)$ & $4(11.8)$ & 0.393 \\
\hline ICU day & $20.2 \pm 15.7$ & $32.1 \pm 21.7$ & $<0.001$ & $19.9 \pm 10.9$ & $33.6 \pm 23.1$ & 0.003 \\
\hline Hospital day & $58.0 \pm 90.1$ & $89.8 \pm 111.2$ & 0.070 & $43.8 \pm 31.2$ & $94.7 \pm 114.7$ & 0.015 \\
\hline ICU-free day, 28 days & $5.2 \pm 8.1$ & $4.8 \pm 7.7$ & 0.822 & $5.1 \pm 7.6$ & $4.9 \pm 7.8$ & 0.962 \\
\hline ICU-free day, 90 days & $29.4 \pm 36.4$ & $34.2 \pm 33.8$ & 0.481 & $32.4 \pm 37.3$ & $35.2 \pm 33.8$ & 0.747 \\
\hline Hospital-free day, 90 days & $16.2 \pm 25.9$ & $14.2 \pm 24.9$ & 0.685 & $16.6 \pm 25.3$ & $14.6 \pm 25.2$ & 0.749 \\
\hline Ventilator-free day, 28 days & $6.4 \pm 8.9$ & $6.1 \pm 8.9$ & 0.898 & $7.1 \pm 8.9$ & $6.3 \pm 8.9$ & 0.737 \\
\hline \multicolumn{7}{|l|}{ Mortality } \\
\hline In ICU mortality & $85(58.6)$ & $17(46.0)$ & 0.166 & $19(55.9)$ & $14(41.2)$ & 0.225 \\
\hline In hospital mortality & $95(65.5)$ & $21(56.8)$ & 0.322 & $20(58.8)$ & $18(52.9)$ & 0.625 \\
\hline At day 28 & $51(35.2)$ & $7(18.9)$ & 0.058 & $10(29.4)$ & $3(8.8)$ & 0.031 \\
\hline At day 90 & $82(56.6)$ & $16(43.2)$ & 0.147 & 18 (52.9) & $13(38.2)$ & 0.223 \\
\hline Tracheostomy & 41 (28.3) & $17(46.0)$ & 0.040 & $12(35.3)$ & $16(47.1)$ & 0.324 \\
\hline Change to portable BiPAP & $8(5.5)$ & $7(18.9)$ & 0.008 & $2(5.9)$ & $7(20.6)$ & 0.074 \\
\hline Reintubation & $25(17.2)$ & $7(18.9)$ & 0.735 & $6(17.7)$ & $6(17.7)$ & 1.000 \\
\hline
\end{tabular}

Values are presented as mean \pm standard deviation or number (\%).

RAS: renin-angiotensin system; ICU: intensive care unit; BiPAP: bilevel positive airway pressure. 
respectively in non-RAS inhibitor group and RAS inhibitor group $(\mathrm{P}=0.774)$. We constructed the propensity score matched cohort, which consisted of 34 patients in each group. Demographic characteristics, comorbidities and mechanical ventilator parameters were similar between two groups in the propensity score matched cohort.

About $60 \%$ of the patients in the RAS inhibitor group had taken $\mathrm{ACE}$ inhibitor or ARB within 1 month before MICU admission (Table 2). In the RAS inhibitor group, 10 patients had been given ACE inhibitor and 27 patients were given ARB.

For the patients receiving ACE inhibitor/ARB, ICU mortality was $45.9 \%$ (17 of 37 patients), which was lower than the $58.9 \%$ mortality rate of patients without medication, though not significantly $(\mathrm{P}=0.166)$ (Table 3$)$. Inhospital mortality was also higher in the non-RAS inhibitor group and the day 28 mortality in non-RAS inhibitor group was almost twice as high without statistical significance $(18.9 \%$ vs. $35.2 \%, \mathrm{P}=0.058)$. In the propensity score matched cohort, in hospital mortality at day 28 was also higher in non-RAS inhibitor group (29.4\%) than RAS inhibitor group $(8.8 \%, \mathrm{P}=0.031)$. However, other parameters of outcome including in hospital mortality at day 90 showed no significant differences between two groups.

ICU-free day at 28 days were about 5 days, similar in

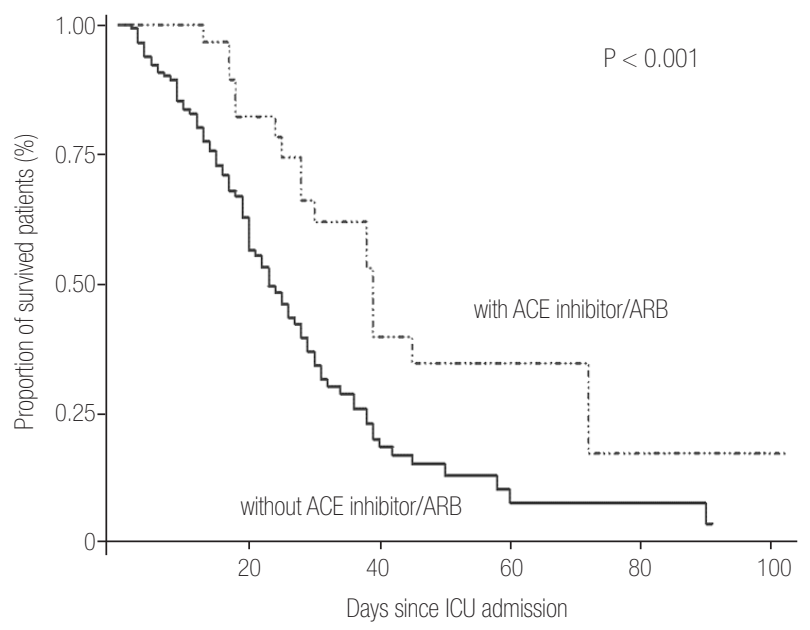

Figure 2. Kaplan-Meier survival analysis. ACE: angiotensinconverting enzyme; ARB: angiotensin receptor blocker; ICU: intensive care unit. both groups $(\mathrm{P}=0.822)$. ICU-free day at 90 days was longer in RAS inhibitor group (mean, 34.2 days) than non-RAS inhibitor group (mean, 29.4 days; $\mathrm{P}=0.481$ ). There was also no significant difference in hospital-free day at 90 days and ventilator-free day at 28 days, between two groups.

The Kaplan-Meier estimate of survival showed a higher mortality rate in non-RAS inhibitor patients $(\mathrm{P}<0.001)$ (Figure 2). Survival analysis after adjustment for propensity score showed similar results in each group $(\mathrm{P}=0.002)$.

\section{Discussion}

Although many studies have been conducted to establish pharmacologic management of patients with ARDS, there is no proven pharmacologic therapy to improve the survival and prognosis of ARDS patients [26]. Clinical trials using well-known anti-inflammatory agents, including corticosteroids, 3-hydroxy-3-methylglutaryl-coenzyme-reductase inhibitors, heparins and aspirin, have not demonstrated clear clinical benefits in ARDS [27-30].

Interestingly, several studies conducted to support antiinflammatory effect of ACE inhibitor in vascular disease [31-33] and also showed protective effect against pneumonia [34,35]. In addition, some animal models have revealed that administration of ACE inhibitor or ARB inhibits fibrosis in the kidneys, heart and liver [36-39]. We therefore tried to evaluate the effect of anti-inflammatory and antifibrotic properties of ACE inhibitor and ARB on outcomes in patients with ARDS.

In this study, radiologic improvement was more frequently detected in the RAS inhibitor group, although this difference was not significant. The mean $\mathrm{PaO}_{2} / \mathrm{FiO}_{2}$ ratio on admission was lower in the RAS inhibitor group than in the non-RAS inhibitor group $(103.1 \pm 51.7$ vs. $112.2 \pm 45.4, \mathrm{P}=0.297)$. However, the ratio increased over time than non-RAS inhibitor group $(187.8 \pm 113.6$ vs. $173.1 \pm 90.9, \mathrm{P}=0.408)$. Clinical improvement in the late phase in regards to chest radiology and oxygenation, might reflect lower degrees in pulmonary sequelae in- 
cluding fibrosis in RAS inhibitor group.

An interesting finding was that the ACE inhibitor group showed greater ICU stay duration and length of mechanical ventilation. Previous studies that conducted survival analysis suggested that surviving patients stayed longer in the ICU $[31,40,41]$. This could explain the differences between the two groups. Considering that no differences in ICU-free day or ventilator-free day, longer duration of ICU or mechanical ventilation could not be affirmed as poor clinical outcome.

More patients in the RAS inhibitor group were transferred to general wards, supported by portable bi-level positive airway pressure ventilators $(18.9 \%$ vs. $5.5 \%, \mathrm{P}=$ 0.008). Considering the similar results in terms of $\mathrm{PaO}_{2} /$ $\mathrm{FiO}_{2}$ ratio and radiologic improvement on discharge, higher dependence on the bi-level positive airway pressure ventilator might be mainly caused by muscle weakness [42].

The mortality rates, both in the ICU and in the hospital, were not different in both groups. The overall mortality rate was high compared to other cohorts, which estimated mortality rates ranged from $28 \%$ to $58 \%[31,43,44]$. It might reflect high disease severity considering high APACHE II score and high proportion of cancer patients in our study [45]. Among the patients who died, the duration of ICU stay was longer $(\mathrm{P}=0.001)$ in the RAS inhibitor group than in the non-RAS inhibitor group, which might explain the lower 28-day mortality rates. Survival analysis showed significantly better survival rates in the RAS inhibitor group. We adjusted confounding factors, including disease severity, using the propensity score, and found the same results as above. The likelihood of survival of patients with ARDS could be improved by the administration of RAS inhibitor.

This study has several limitations. First, ARDS is a complicated syndrome, and it is difficult to distinguish ARDS from other diseases that might cause radiologic abnormality and respiratory failure. However, we did our best to overcome the weakness of the retrospective design. We reviewed all medical records, including echocardiography results, daily body weight changes and vital sign changes, to evaluate volume status. Records of physical examination and assessment by medical attendance were also reviewed to exclude other diseases. Second, ACE inhibitors or ARB administered to patients did not have uniform component or dosage. However, for the treatment of hypertension, ACE inhibitor and ARB showed similar efficacy in lowering blood pressure $[46,47]$. Though the mechanisms of action between ACE inhibitor and ARB are different, there was no relevant difference in clinical outcomes for renal protection [48]. Further researches are needed to compare efficacy in anti-inflammatory effect. Third, the sample size was relatively small, and a considerable number of patients had many comorbidities. These confounding factors might have influenced the outcome [49].

In conclusion, in this study we found that ACE inhibitor or ARB may have beneficial effect on ARDS patients. We need large prospective clinical study to validate this finding.

\section{ORCID}

Joohae Kim http://orcid.org/0000-0002-1461-4850

Sang-Min Lee http://orcid.org/0000-0002-1388-9318

\section{References}

1. Ware LB, Matthay MA. The acute respiratory distress syndrome. N Engl J Med 2000;342:1334-49.

2. Bernard GR, Artigas A, Brigham KL, Carlet J, Falke K, Hudson L, et al. The American-European Consensus Conference on ARDS: definitions, mechanisms, relevant outcomes, and clinical trial coordination. Am J Respir Crit Care Med 1994;149(3 Pt 1):818-24.

3. Krafft P, Fridrich P, Pernerstorfer T, Fitzgerald RD, Koc D, Schneider B, et al. The acute respiratory distress syndrome: definitions, severity and clinical outcome. An analysis of 101 clinical investigations. Intensive Care Med 1996;22:519-29. 
4. Phua J, Badia JR, Adhikari NK, Friedrich JO, Fowler RA, Singh JM, et al. Has mortality from acute respiratory distress syndrome decreased over time? A systematic review. Am J Respir Crit Care Med 2009;179:220-7.

5. Abel SJ, Finney SJ, Brett SJ, Keogh BF, Morgan CJ, Evans TW. Reduced mortality in association with the acute respiratory distress syndrome (ARDS). Thorax 1998;53:292-4.

6. Erickson SE, Martin GS, Davis JL, Matthay MA, Eisner MD; NIH NHLBI ARDS Network. Recent trends in acute lung injury mortality: 1996-2005. Crit Care Med 2009;37:1574-9.

7. Pugin J, Verghese G, Widmer MC, Matthay MA. The alveolar space is the site of intense inflammatory and profibrotic reactions in the early phase of acute respiratory distress syndrome. Crit Care Med 1999;27:304-12.

8. Marshall R, Bellingan G, Laurent G. The acute respiratory distress syndrome: fibrosis in the fast lane. Thorax 1998;53:815-7.

9. McClintock D, Zhuo H, Wickersham N, Matthay MA, Ware LB. Biomarkers of inflammation, coagulation and fibrinolysis predict mortality in acute lung injury. Crit Care 2008;12:R41.

10. Meduri GU, Headley S, Kohler G, Stentz F, Tolley E, Umberger R, et al. Persistent elevation of inflammatory cytokines predicts a poor outcome in ARDS: plasma IL-1 beta and IL-6 levels are consistent and efficient predictors of outcome over time. Chest 1995;107:1062-73.

11. Bhatia M, Moochhala S. Role of inflammatory mediators in the pathophysiology of acute respiratory distress syndrome. J Pathol 2004;202:145-56.

12. Burnham EL, Janssen WJ, Riches DW, Moss M, Downey GP. The fibroproliferative response in acute respiratory distress syndrome: mechanisms and clinical significance. Eur Respir J 2014;43:276-85.

13. Quesnel C, Piednoir P, Gelly J, Nardelli L, Garnier $\mathrm{M}$, Lecon $\mathrm{V}$, et al. Alveolar fibrocyte percentage is an independent predictor of poor outcome in patients with acute lung injury. Crit Care Med 2012;40:21-8.

14. Martin C, Papazian L, Payan MJ, Saux P, Gouin F. Pulmonary fibrosis correlates with outcome in adult respiratory distress syndrome: a study in mechanically ventilated patients. Chest 1995;107:196-200.

15. Kranzhofer R, Browatzki M, Schmidt J, Kubler W. Angiotensin II activates the proinflammatory transcription factor nuclear factor-kappaB in human monocytes. Biochem Biophys Res Commun 1999;257:826-8.

16. Hernandez-Presa M, Bustos C, Ortego M, Tunon J, Renedo G, Ruiz-Ortega M, et al. Angiotensin-converting enzyme inhibition prevents arterial nuclear factor-kappa B activation, monocyte chemoattractant protein-1 expression, and macrophage infiltration in a rabbit model of early accelerated atherosclerosis. Circulation 1997;95:1532-41.

17. Arndt PG, Young SK, Poch KR, Nick JA, Falk S, Schrier RW, et al. Systemic inhibition of the angiotensin-converting enzyme limits lipopolysaccharideinduced lung neutrophil recruitment through both bradykinin and angiotensin II-regulated pathways. J Immunol 2006;177:7233-41.

18. He X, Han B, Mura M, Xia S, Wang S, Ma T, et al. Angiotensin-converting enzyme inhibitor captopril prevents oleic acid-induced severe acute lung injury in rats. Shock 2007;28:106-11.

19. Wang R, Ibarra-Sunga O, Verlinski L, Pick R, Uhal BD. Abrogation of bleomycin-induced epithelial apoptosis and lung fibrosis by captopril or by a caspase inhibitor. Am J Physiol Lung Cell Mol Physiol 2000;279:L143-51.

20. Cohen EP, Molteni A, Hill P, Fish BL, Ward WF, Moulder JE, et al. Captopril preserves function and ultrastructure in experimental radiation nephropathy. Lab Invest 1996;75:349-60.

21. Molteni A, Moulder JE, Cohen EF, Ward WF, Fish BL, Taylor JM, et al. Control of radiation-induced pneumopathy and lung fibrosis by angiotensin-converting enzyme inhibitors and an angiotensin II type 1 receptor blocker. Int J Radiat Biol 2000;76:523-32. 
22. Brooks WW, Bing OH, Robinson KG, Slawsky MT, Chaletsky DM, Conrad CH. Effect of angiotensinconverting enzyme inhibition on myocardial fibrosis and function in hypertrophied and failing myocardium from the spontaneously hypertensive rat. Circulation 1997;96:4002-10.

23. Ishidoya S, Morrissey J, McCracken R, Reyes A, Klahr S. Angiotensin II receptor antagonist ameliorates renal tubulointerstitial fibrosis caused by unilateral ureteral obstruction. Kidney Int 1995;47:128594.

24. Schieffer B, Wirger A, Meybrunn M, Seitz S, Holtz J, Riede UN, et al. Comparative effects of chronic angiotensin-converting enzyme inhibition and angiotensin II type 1 receptor blockade on cardiac remodeling after myocardial infarction in the rat. Circulation 1994;89:2273-82.

25. ARDS Definition Task Force, Ranieri VM, Rubenfeld GD, Thompson BT, Ferguson ND, Caldwell E, et al. Acute respiratory distress syndrome: the Berlin Definition. JAMA 2012;307:2526-33.

26. Frank AJ, Thompson BT. Pharmacological treatments for acute respiratory distress syndrome. Curr Opin Crit Care 2010;16:62-8.

27. National Heart, Lung, and Blood Institute ARDS Clinical Trials Network, Truwit JD, Bernard GR, Steingrub J, Matthay MA, Liu KD, et al. Rosuvastatin for sepsis-associated acute respiratory distress syndrome. N Engl J Med 2014;370:2191-200.

28. Kor DJ, Iscimen R, Yilmaz M, Brown MJ, Brown DR, Gajic O. Statin administration did not influence the progression of lung injury or associated organ failures in a cohort of patients with acute lung injury. Intensive Care Med 2009;35:1039-46.

29. Jaimes F, De La Rosa G, Morales C, Fortich F, Arango C, Aguirre D, et al. Unfractioned heparin for treatment of sepsis: a randomized clinical trial (the HETRASE study). Crit Care Med 2009;37:1185-96.

30. Kor DJ, Erlich J, Gong MN, Malinchoc M, Carter RE, Gajic O, et al. Association of prehospitalization aspirin therapy and acute lung injury: results of a multicenter international observational study of atrisk patients. Crit Care Med 2011;39:2393-400.

31. Rubenfeld GD, Caldwell E, Peabody E, Weaver J, Martin DP, Neff M, et al. Incidence and outcomes of acute lung injury. N Engl J Med 2005;353:1685-93.

32. Moss M, Gillespie MK, Ackerson L, Moore FA, Moore EE, Parsons PE. Endothelial cell activity varies in patients at risk for the adult respiratory distress syndrome. Crit Care Med 1996;24:1782-6.

33. Conner ER, Ware LB, Modin G, Matthay MA. Elevated pulmonary edema fluid concentrations of soluble intercellular adhesion molecule-1 in patients with acute lung injury: biological and clinical significance. Chest 1999;116(1 Suppl):83S-4S.

34. Flori HR, Ware LB, Glidden D, Matthay MA. Early elevation of plasma soluble intercellular adhesion molecule- 1 in pediatric acute lung injury identifies patients at increased risk of death and prolonged mechanical ventilation. Pediatr Crit Care Med 2003;4:315-21.

35. Parsons PE, Eisner MD, Thompson BT, Matthay MA, Ancukiewicz M, Bernard GR, et al. Lower tidal volume ventilation and plasma cytokine markers of inflammation in patients with acute lung injury. Crit Care Med 2005;33:1-6.

36. Seccia TM, Belloni AS, Guidolin D, Sticchi D, Nussdorfer GG, Pessina AC, et al. The renal antifibrotic effects of angiotensin-converting enzyme inhibition involve bradykinin $\mathrm{B} 2$ receptor activation in angiotensin II-dependent hypertension. J Hypertens 2006;24:1419-27.

37. Yamamoto K, Mano T, Yoshida J, Sakata Y, Nishikawa N, Nishio M, et al. ACE inhibitor and angiotensin II type 1 receptor blocker differently regulate ventricular fibrosis in hypertensive diastolic heart failure. J Hypertens 2005;23:393-400.

38. Karimian G, Mohammadi-Karakani A, Sotoudeh M, Ghazi-Khansari M, Ghobadi G, Shakiba B. Attenuation of hepatic fibrosis through captopril and enalapril in the livers of bile duct ligated rats. Biomed Pharmacother 2008;62:312-6. 
39. Jonsson JR, Clouston AD, Ando Y, Kelemen LI, Horn MJ, Adamson MD, et al. Angiotensin-converting enzyme inhibition attenuates the progression of rat hepatic fibrosis. Gastroenterology 2001;121:148-55.

40. Needham DM, Colantuoni E, Mendez-Tellez PA, Dinglas VD, Sevransky JE, Dennison Himmelfarb $\mathrm{CR}$, et al. Lung protective mechanical ventilation and two year survival in patients with acute lung injury: prospective cohort study. BMJ 2012;344:e2124.

41. Herridge MS, Cheung AM, Tansey CM, MatteMartyn A, Diaz-Granados N, Al-Saidi F, et al. Oneyear outcomes in survivors of the acute respiratory distress syndrome. N Engl J Med 2003;348:683-93.

42. Angel MJ, Bril V, Shannon P, Herridge MS. Neuromuscular function in survivors of the acute respiratory distress syndrome. Can J Neurol Sci 2007;34:427-32.

43. Villar J, Sulemanji D, Kacmarek RM. The acute respiratory distress syndrome: incidence and mortality, has it changed? Curr Opin Crit Care 2014;20:3-9.

44. MacCallum NS, Evans TW. Epidemiology of acute lung injury. Curr Opin Crit Care 2005;11:43-9.

45. Soubani AO, Shehada E, Chen W, Smith D. The outcome of cancer patients with acute respiratory distress syndrome. J Crit Care 2014;29:183.e7-183.

46. Matchar DB, McCrory DC, Orlando LA, Patel MR, Patel UD, Patwardhan MB, et al. Systematic review: comparative effectiveness of angiotensin-converting enzyme inhibitors and angiotensin II receptor blockers for treating essential hypertension. Ann Intern Med 2008;148:16-29.

47. Vega IL. ACE inhibitors vs ARBs for primary hypertension. Am Fam Physician 2015;91:522-3.

48. Laverman GD, Remuzzi G, Ruggenenti P. ACE inhibition versus angiotensin receptor blockade: which is better for renal and cardiovascular protection? J Am Soc Nephrol 2004;15 Suppl 1:S64-70.

49. Wang CY, Calfee CS, Paul DW, Janz DR, May AK, Zhuo H, et al. One-year mortality and predictors of death among hospital survivors of acute respiratory distress syndrome. Intensive Care Med 2014;40:388-96. 